\title{
Siglen, Zeichen, Abkürzungen
}

Aufstellung der in diesem Band verwendeten Siglen, Zeichen und Abkürzungen gemäß den Editorischen Grundsätzen der Ernst Troeltsch · Kritische Gesamtausgabe

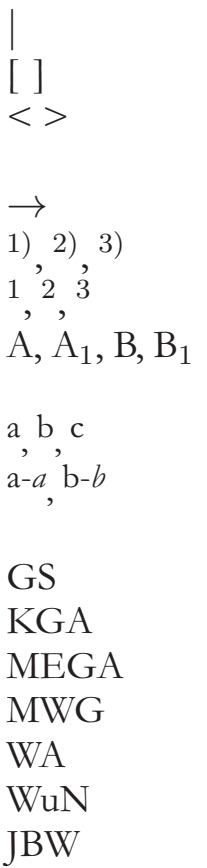

Seitenwechsel

Hinzufügung des Editors

Hinzufügungen des Edierten Textes gegenüber den vorangegangenen Textstufen $\mathrm{A}$ und $\mathrm{A}_{1}$

Siehe

Indices bei Fußnoten Ernst Troeltschs

Indices bei Kommentaranmerkungen des Herausgebers

Siglen für die Textfassungen in chronologischer Reihenfolge

Indices für Varianten oder textkritische Anmerkungen

Beginn und Ende von Varianten oder Texteingriffen

Ernst Troeltsch: Gesammelte Schriften

Ernst Troeltsch - Kritische Gesamtausgabe

Karl Marx Friedrich Engels Gesamtausgabe

Max Weber-Gesamtausgabe

D. Martin Luthers Werke. Weimarer Ausgabe

Franz Overbeck: Werke und Nachlaß

Jacob Burckhardt Werke. Kritische Gesamtausgabe

Alle sonstigen Abkürzungen folgen: Siegfried Schwertner: Internationales Abkürzungsverzeichnis für Theologie und Grenzgebiete, 2. Auflage, Berlin, New York: Walter de Gruyter, 1992. 
